\title{
Impacto de los sistemas silvopastoriles en la calidad del agua de dos microcuencas ganaderas de Matiguás, Nicaragua
}

Aura Y. Cárdenas ${ }^{1}$, Bismark Reyes ${ }^{2}$, Ney Ríos ${ }^{3}$, Alfredo Woo ${ }^{4}$, Elías Ramírez ${ }^{5}$ y Muhammad

Ibrahim $^{6}$

1 Mon. Agua y SIG. Proyecto GEF-Silvopastoril, Instituto de Investigación y Desarrollo Nitlapan, Universidad Centroamericana. E-mail: auracard@ns.uca.edu.ni, aycardenas@gmail.com

2 Asistente local para monitoreo de calidad de agua en microcuencas ganaderas.

3 Consultor internacional sobre manejo de cuencas hidrográficas. E-mail: jrios@catie.ac.cr

4 Asistente local para monitoreo de usos de suelo.

5 Coordinador Nacional Proyecto GEF-Silvopastoril, Instituto de Investigación y Desarrollo Nitlapan, Universidad Centroamericana. E-mail: nitlactaf@ns.uca.edu.ni

6 Coordinador del grupo Gamma, CATIE. E-mail: mibrahim@catie.ac.cr

Recibido: junio de 2007 / Aceptado: julio de 2007

EN EL PRESENTE ESTUDIO SE EVALUÓ EL IMPACTO DE LOS SISTEMAS silvopastoriles en la calidad del agua de las microcuencas de los ríos Bul bul y Paiwas, Matiguás, Nicaragua. Se seleccionaron 9 quebradas, 5 protegidas por bosque ripario y 4 no protegidas, ubicadas en fincas con sistemas silvopastoriles. Se establecieron 2 puntos de monitoreo por quebrada: a $50 \mathrm{~m}$ de distancia de la naciente y en la zona de potreros. Se tomaron muestras de agua a las que se les realizó análisis físicoquímicos y bacteriológicos. En la época seca se registraron niveles bajos de O2D (oxígeno disuelto $\mathrm{mg} / \mathrm{L}$ ) y niveles altos de dureza total $\mathrm{mg} / \mathrm{L}$, mientras que en la época lluviosa se encontraron los niveles más altos de coliformes fecales. El resto de los parámetros evaluados fueron aptos para consumo humano. Se encontraron diferencias significativas a un $(\mathrm{P}<0,05)$ entre épocas para $\mathrm{O} 2 \mathrm{D} \mathrm{mg} / \mathrm{L}$ y dureza total $\mathrm{mg} / \mathrm{L}$.

Palabras clave: calidad del agua-investigaciones / análisis del agua / ganaderíaMatiguás, Matagalpa (Nicaragua) / contaminación del agua

\section{Introducción}

El proceso de degradación de los recursos naturales afecta suelos, bosques, tierras agrícolas y ecosistemas acuáticos (Hillel, 1991), incrementando la carga de sedimentos, concentraciones 
de sales y metales, y de agentes patógenos (Rojas, 1987). Una de las principales causas de esta degradación es el crecimiento demográfico (WRI, 1999), que reduce considerablemente la disponibilidad percápita de agua, aumenta la presión sobre los bosques, incrementa el material vegetal en descomposición y disminuye la absorción de nutrientes de la vegetación (Bruijinzeel, 1990).

Las prácticas ganaderas tradicionales como el sobre pastoreo en zonas de laderas, el manejo inadecuado de los suelos con vocación forestal y el avance de la frontera agrícola, son las principales causas del deterioro de los recursos naturales (UICN, 2001), en especial de la vegetación riparia, ya que la compactación de suelos bajo pastoreo intensivo reduce la infiltración e incrementa la escorrentía superficial y la deposición de material orgánico en los cauces (Lowrance et al., 2002).

Esta situación ha generado la necesidad de fomentar proyectos de recuperación de pasturas degradadas que disminuyan los problemas ambientales derivados de las actividades agropecuarias mediante la aplicación de modelos alternativos de producción, tales como los sistemas silvopastoriles (Ibrahim, et al., 1996; Szott et al., 2000). Por este motivo, se analizó el efecto de los sistemas silvopastoriles en la calidad del agua tomando en cuenta el cambio en los usos del suelo en las microcuencas de los ríos Bul Bul y Paiwitas en Matiguás, Nicaragua.

\section{Metodología}

\section{1. Área de estudio}

El municipio de Matiguás está ubicado en el centro geográfico de Nicaragua, con una topografía que oscila entre los 200 y 400 metros sobre el nivel del mar. Se localiza entre las coordenadas $85^{\circ}$ y $27^{\circ}$ de latitud norte, $12^{\circ}$ y $50^{\circ}$ de longitud oeste. Posee un régimen de lluvias que oscila entre 1,200 y 1,800 mm. anuales, con una distribución de mayo a diciembre (Guerrero \& Soriano, 1992). Los usos de suelo que predominan son los pastizales y tacotales, y la principal actividad económica es la ganadería de leche y carne (Ruíz, 2002).

Se seleccionaron 9 quebradas (5 protegidas por bosque ripario y 4 sin protección) ubicadas en dos microcuencas: 6 quebradas en la microcuenca del Río Paiwitas y 3 quebradas en la microcuenca del Río Bul Bul (Cuadro 1). Los criterios que se utilizaron para establecer los puntos de muestreo fueron los siguientes:

a. Para las quebradas protegidas, que fueran quebradas con caudal permanente y protegido por bosque ripario, tanto la naciente como el recorrido de la misma.

b. Para las quebradas sin protección, que fueran quebradas en potreros, sin protección de bosque ripario, tanto en la naciente como en el recorrido de la misma.

A nivel de microcuenca se identificaron los sistemas silvopastoriles presentes y las actividades productivas vinculadas a la producción pecuaria (establos y corrales) que podrían generar zonas de mayor vulnerabilidad en la contaminación del agua. 
Se seleccionaron estaciones de monitoreo en las quebradas dentro de las cuales se establecieron 2 puntos de muestreo, el primero a $50 \mathrm{~m}$ de distancia de la naciente de agua y el segundo en la zona de los potreros.

Se hicieron dos muestreos representativos de la estación climática siguiendo las recomendaciones de Molliner \& Camacho (2002).

Cuadro 1. Descripción de las quebradas que se monitorearon en las microcuencas de los ríos Bul Bul y Paiwitas en Matiguás, Nicaragua (2005- 2006)

\begin{tabular}{|l|l|l|} 
Micro cuenca & Quebrada & Descripción \\
\hline Paiwitas & 1 & $\begin{array}{l}\text { Zona sin protección, dentro de banco forrajero de gramíneas } \\
\text { Protegido por bosque ripario, pastura mejorada con alta } \\
\text { densidad de árboles } \\
\text { Protegido por bosque ripario, pasturas mejoradascon baja } \\
\text { densidad de árboles, pastura mejorada con alta densidad de } \\
\text { árboles } \\
\text { Zona sin protección en pasturas, zona de pastoreo, pasturas } \\
\text { mejoradas } \\
\text { Protegido por bosque ripario, pasturas degradadas } \\
\text { No protegida en la naciente, pasturas degradadas }\end{array}$ \\
\hline Bul Bul & 5 & $\begin{array}{l}\text { Protegido, pastura mejorada con alta densidad de árboles } \\
\text { Protegido, pastura mejorada con alta densidad de árboles } \\
\text { Cultivos, sin protección, piscina (tilapias), pastos } \\
\text { mejorados, residuos vivienda }\end{array}$ \\
\hline & 7 & \multicolumn{1}{|l}{} \\
\hline
\end{tabular}

\subsection{Análisis físico-químico y bacteriológico de la calidad del agua}

Se tomaron 90 muestras para el análisis físico-químico y bacteriológico en las 9 quebradas, en 5 repeticiones - agosto septiembre, noviembre (época lluviosa); febrero, mayo (época seca).

Los parámetros seleccionados para este análisis fueron: demanda bioquímica de oxígeno (DBO) (mg/l), dureza total (mg/l), coliformes fecales (NMP/100ml), Fósforo total (mg/l), nitratos (mg/l) y sólidos suspendidos $(\mathrm{mg} / \mathrm{L})$. También se tomaron algunos parámetros en campo como: Oxígeno disuelto $(\mathrm{mg} / \mathrm{l})$, potencial Hidrógeno $(\mathrm{pH})$, temperatura $\left({ }^{\circ} \mathrm{C}\right)$ y conductividad eléctrica (ms/cm).

\subsection{Análisis estadístico}

El diseño experimental fue por muestreo estratificado tomando en consideración cobertura arbórea y usos de suelo. A los resultados de laboratorio y de campo se les aplicó un análisis de varianza (ANDEVA) utilizando el programa estadístico InfoStat (2002). 


\section{Resultados y discusión}

\subsection{Análisis fisicoquímicos}

\section{Oxígeno disuelto (O2D)}

Los rangos de O2D oscilaron entre $3,6 \mathrm{mg} / \mathrm{l}$ para la época seca y 5,3 mg/l para la época lluviosa con diferencias significativas entre sí $(\mathrm{P}<0,05)$. Para quebradas protegidas y desprotegidas se encontraron diferencias aunque no fueron significativas estadísticamente (Ilustración 1).

El O2D fue un parámetro importante para determinar la calidad del agua, ya que nos permitió evaluar los efectos de potenciales agentes contaminantes en los puntos de muestreo. La baja solubilidad del oxígeno encontrada nos mostró que éste es uno de los principales factores que está limitando la capacidad de purificación de las aguas naturales monitoreadas. Estos niveles están asociados a las descargas directas de materias orgánicas e inorgánicas en las fuentes de agua, que son utilizadas en su mayoría como abrevaderos, para lavado de pichingas, para el paso de bestias, como depósito de aguas residuales de actividades domésticas (agua con detergentes y cloros), etc.
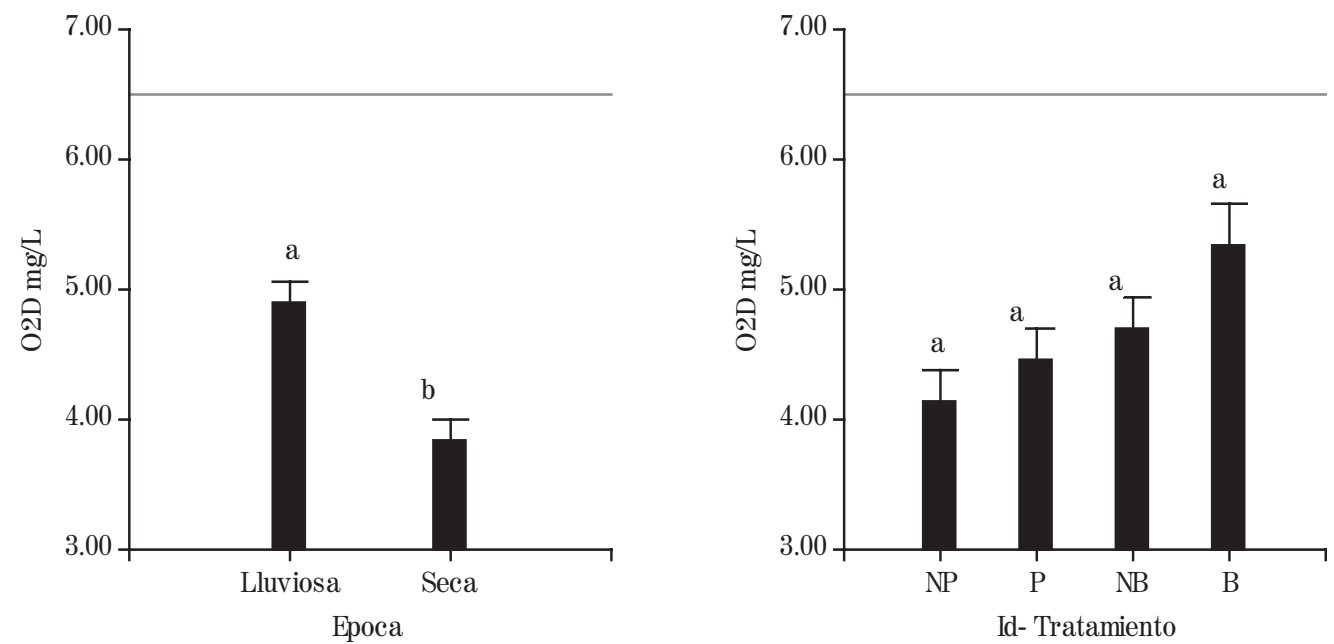

Letras diferentes indican diferencias significativas. Duncan $\mathrm{p}<0,05$ $\mathrm{NP}=$ No protegido, $\mathrm{P}=$ Potrero, $\mathrm{NB}=$ Naciente con bosque, $\mathrm{B}=$ Bosque

Ilustración 1. Niveles de oxígeno disuelto en las épocas de muestreo y en los diferentes usos de suelo en las microcuencas de los ríos Bul bul y Paiwitas, Matiguás, Nicaragua, (2005- 2006)

\section{Dureza total}

Los valores de dureza total obtenidos en las quebradas por épocas, y entre quebradas 
protegidas y no protegidas, presentaron niveles permisibles para consumo humano, siendo aguas moderadamente duras (Cuadro 2).

Se encontraron diferencias significativas entre épocas $(\mathrm{P}<0,05)$, con los niveles más altos para la época seca. Esto se atribuye directamente al bajo caudal de las quebradas en este período, permitiéndose de esta manera una mayor concentración de las sales en el agua. Asimismo, se encontró que en las quebradas no protegidas y con influencia de potreros, los niveles tienden a aumentar especialmente por el arrastre de sales y minerales provenientes de la fertilización del suelo que se va a las fuentes de agua por escorrentía (Ilustración 2).
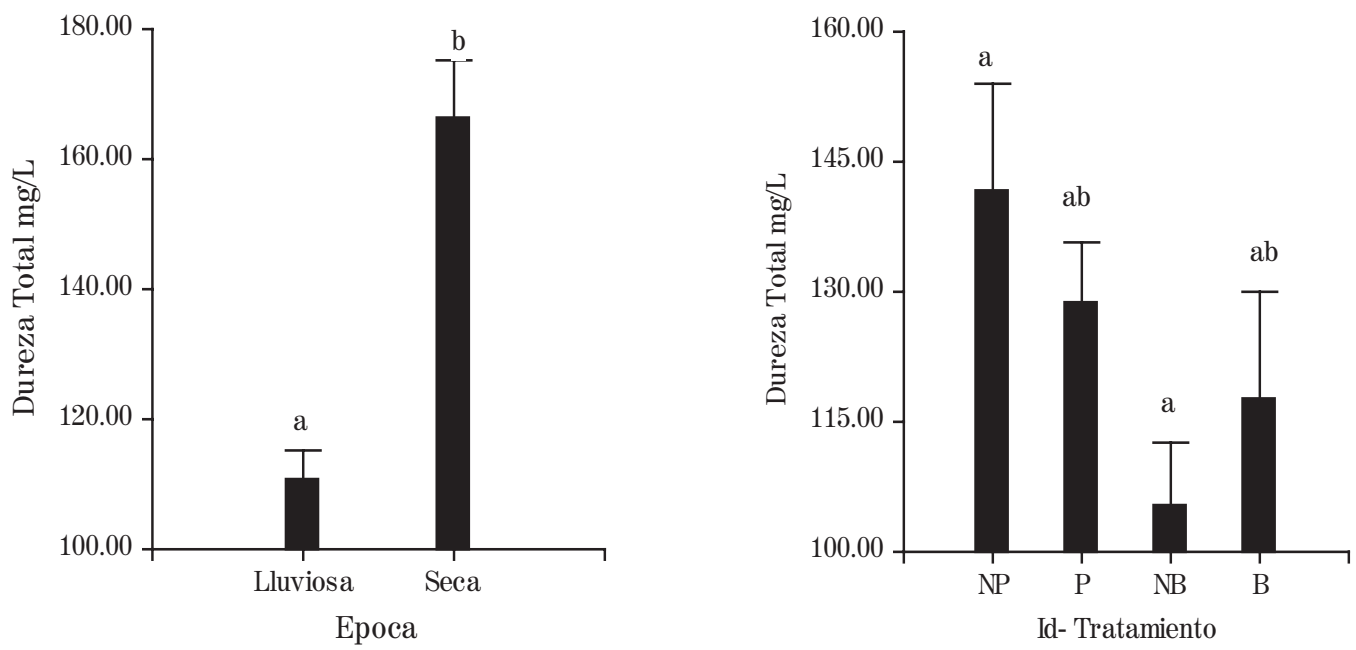

Letras diferentes indican diferencias significativas. Duncan $\mathrm{p}<0,05$

$\mathrm{NP}=$ No protegido, $\mathrm{P}=$ Potrero, $\mathrm{NB}=$ Naciente con bosque, $\mathrm{B}=$ Bosque

Ilustración 2. Niveles de dureza total en las épocas de muestreo y en los diferentes usos de suelo en las microcuencas de los ríos Bul bul y Paiwitas, Matiguás, Nicaragua, (2005- 2006)

\section{Fósforo}

Los valores recomendable de Fósforo disuelto en el agua para consumo humano son de 0,40 $\mathrm{mg} / \mathrm{l}$ hasta 5,0 mg/l, y los niveles encontrados oscilaron entre $0,12 \mathrm{mg} / \mathrm{l}$ para quebradas no protegidas y $0,01 \mathrm{mg} / \mathrm{l}$ para quebradas protegidas, indicando que los niveles de fósforo son bajos y están dentro del rango permisible para consumo humano (Ilustración 3). 

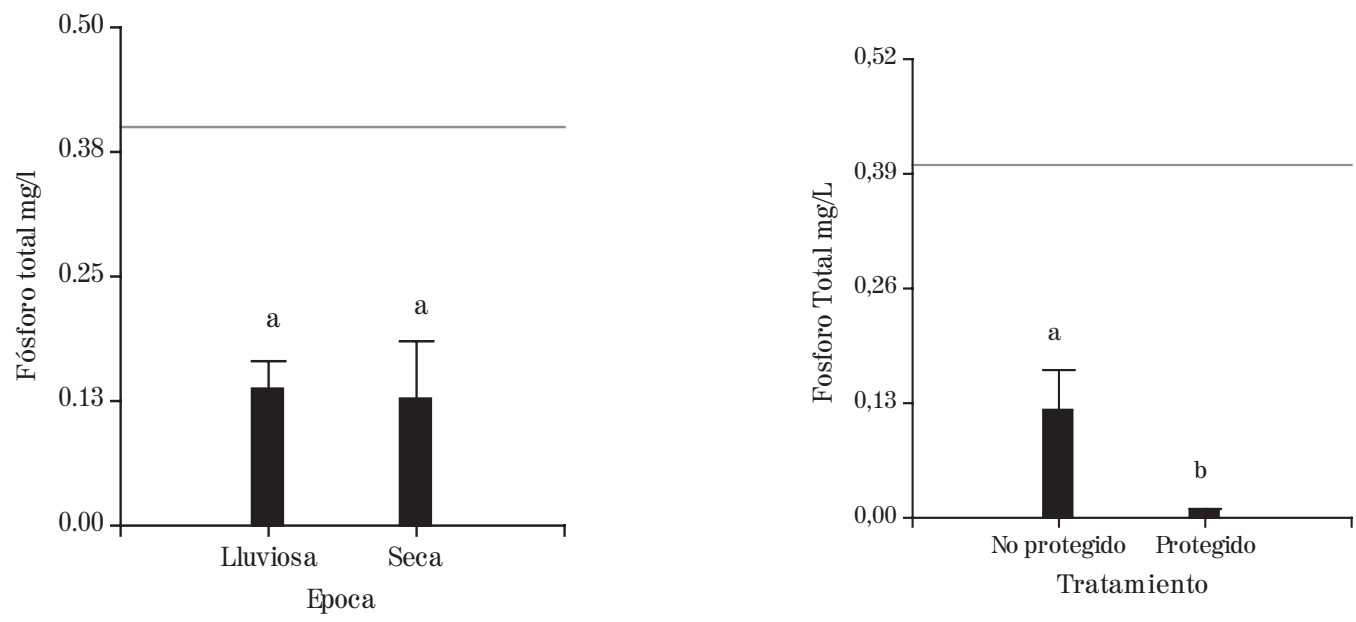

Letras diferentes indican diferencias significativas. Duncan $\mathrm{p}<0,05$.

Ilustración 3. Niveles de Fósforo en las épocas de muestreo y quebradas protegidas y no protegidas de las microcuencas del río Bul bul y Paiwitas, Matiguás, Nicaragua, (20052006)

El resto de los parámetros, tales como: potencial de Hidrógeno $(\mathrm{pH})$, demanda bioquímica de Oxígeno $(\mathrm{mg} / \mathrm{L})$, conductividad $(\mu \mathrm{S} / \mathrm{cm})$, nitratos $(\mathrm{mg} / \mathrm{L})$ y sólidos suspendidos $(\mathrm{mg} / \mathrm{L})$, alcanzaron valores que están dentro de un rango permisible según las normas CAPRE para Nicaragua (Cuadro 2).

Cuadro 2. Parámetros fisicoquímicos y bacteriológicos promedio (DS) del agua en quebradas de las microcuencas de los ríos Bul Bul y Paiwitas, Matiguás, Nicaragua (2005- 2006)

\begin{tabular}{|l|r|r|r|}
\hline & \multicolumn{2}{c}{$\begin{array}{l}\text { Quebradas no } \\
\text { Variable }\end{array}$} & \multicolumn{2}{c|}{ Quebradas protegidas } & \multicolumn{1}{l|}{$\begin{array}{l}\text { Probabilidad } \\
(<0,05)\end{array}$} \\
\hline \multicolumn{1}{|c|}{$\mathrm{pH}$} & $28,89( \pm 2,09) \mathrm{a}$ & $5,93( \pm 2,62) \mathrm{a}$ & 0,9480 \\
\hline Conductividad $(\mathrm{uS} / \mathrm{cm})$ & $3,35( \pm 2,16) \mathrm{b}$ & $4,67( \pm 1,52) \mathrm{a}$ & 0,0062 \\
\hline Oxígeno disuelto $(\mathrm{mg} /) \mathrm{l}$ & $1,2( \pm 1,6) \mathrm{a}$ & $1,02( \pm 1,5) \mathrm{a}$ & 0,0474 \\
\hline DBO5 $(\mathrm{mg} / \mathrm{l})$ & $32,98( \pm 132,16) \mathrm{a}$ & $5,97( \pm 3,37) \mathrm{a}$ & 0,3027 \\
\hline NNH3 (mg/l) & $38,1( \pm 7,0) \mathrm{a}$ & $14,20( \pm 20,79) \mathrm{a}$ & 0,1964 \\
\hline Sólidos suspendidos $(\mathrm{mg} / \mathrm{l})$ & $7908,15( \pm 6672,36) \mathrm{a}$ & $7561,54( \pm 54,83) \mathrm{a}$ & 0,8375 \\
\hline $\begin{array}{l}\text { Colifor mes totales } \\
(\mathrm{NMP} / 100)\end{array}$ & $1356,67( \pm 3208,05) \mathrm{a}$ & $1469,48( \pm 3544,79) \mathrm{a}$ & 0,9046 \\
\hline $\begin{array}{l}\text { Coliformes fecales } \\
(\mathrm{NMP} / 100)\end{array}$ & $0,12( \pm 0,23) \mathrm{a}$ & $0,01( \pm 0,01) \mathrm{b}$ & 0,0155 \\
\hline Fósforo $(\mathrm{mg} / \mathrm{l})$ & & & \\
\hline
\end{tabular}

Letras diferentes entre columnas indican diferencias significativas. Duncan $\mathrm{p}<0,05$ 


\section{Análisis bacteriológico}

En lo que respecta a coliformes fecales se encontraron niveles altos en la época de invierno (Ilustración 4). Esto se debe a las cantidades de materia orgánica y fecal arrastradas por medio de la escorrentía superficial y depositadas en las quebradas, y al acceso directo de los animales a los cuerpos de agua. Los niveles en la época seca fueron significativamente menores $(\mathrm{P}<0,05)$. Pero en general hay contaminación alta en las diferentes épocas y en quebradas protegidas y desprotegidas, superando los valores críticos (ver en anexo normas CAPRE para Nicaragua).
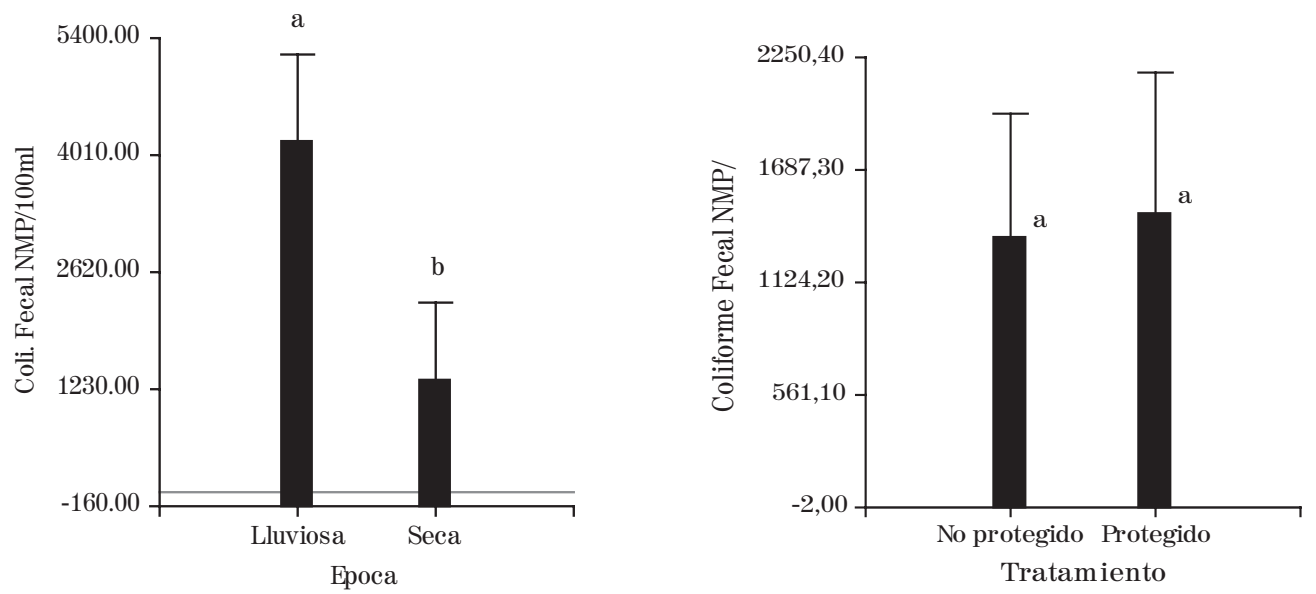

Ilustración 4. Niveles de coliformes fecales en las épocas de muestreo y quebradas protegidas y no protegidas de las microcuencas de los ríos Bul Bul y Paiwitas, Matiguás, Nicaragua, (2005- 2006)

\section{Conclusiones y recomendaciones}

- La calidad del agua es inversamente proporcional al nivel de intervención que hay en los cuerpos de agua, encontrándose que los usos de suelo que tienen una franja de bosque ripario densa y menos intervención del hombre (actividades productivas como la ganadería) poseen una mejor calidad de agua.

- Es necesario implementar sistemas silvopastoriles en zonas de protección ya que cuando se asocia pasto, vegetación arbustiva y arbórea, se pueden atrapar sedimentos y nutrientes, teniendo efectos positivos en la salud de los sistemas acuáticos.

- Los coliformes fecales constituyen uno de los indicadores más importantes de la calidad del agua para consumo humano por encontrarse distribuidos ampliamente en el medioambiente. Podemos decir que las aguas evaluadas en este estudio no son bacteriológicamente seguras para consumo humano, aunque sí se pueden usar en otras actividades productivas. 


\section{Referencias bibliográficas}

BRUIJINZEEL, L. (1990). Hydrology of MoistTropical Forest and Effects of Conversion. UNESCO International Hydrological programme: Francia.

GUERRERO, A. \& SORIANO, C. (1992). Monografías de Matagalpa 27p. Disponible en: www.inifom.gov.ni/caracter/información/Matagalpa/matiguas. Consultada en febrero de 2006.

HILLEL, D. (1991). Out of the Earth. Civilization and the Life of the Soil. Aurum press Ltd.: London.

IBRAHIM, et al. (1996). Sistemas silvopastoriles. Módulo de enseñanza forestal. Turrialba, Costa Rica. No.2. 275p. 2da. ed.

INFOSTAT (2002). InfoStat versión 1.1. Grupo InfoStat, FCA, Universidad Nacional de Córdoba: Córdoba, Argentina.

LOWRANCE et al. (2002). "Improving Water and Soil Quality with Conservation Buffer". En Journal of Soil and Water Conservation. 57: 38-46.

ROJAS, R. (1987). Seminario sobre el desarrollo de pequeñas cuencas hidrográficas. "La pequeña cuenca como abastecedora de agua". Desarrollo rural integrado CIBAD occidental: Santiago, Chile.

RUíZ, A. (2002). Fijación y almacenamiento de carbono en sistemas silvopastoriles y competitividad económica en Matiguás, Nicaragua. Tesis Mag. Sc. CATIE: Turrialba, Costa Rica, 106p.

SZOTT, L.; IBRAHIM, M. \& BEER, J. (2000). The Hamburger Connection Hangover. Cattle Pasture Land Degradation and Alternative Land Use in Central America. CATIE, DANIDA, GTZ: Turrialba, Costa Rica.

UICN. (2001). Iniciativa de agua y naturaleza. Estrategia y proyecto de UICN para Mesoamérica, Disponible en: http://www.tierramerica.net/2003. Consultada el 26 de julio de 2006.

MOLLINER, A. \& CAMACHO, A. (2002). Recomendaciones para la toma de muestras de agua, biota y sedimentos en Humedales Ramsar. Ministerio de Medioambiente: Madrid.

WRI (1999). World Resources 1998- 99. A Guide to the Global Environment. Oxford, Reino Unido: Oxford University Press 


\section{Anexo}

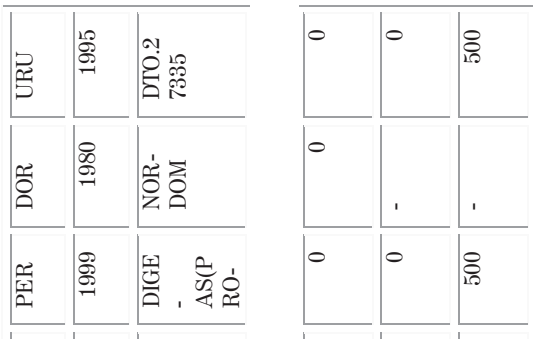

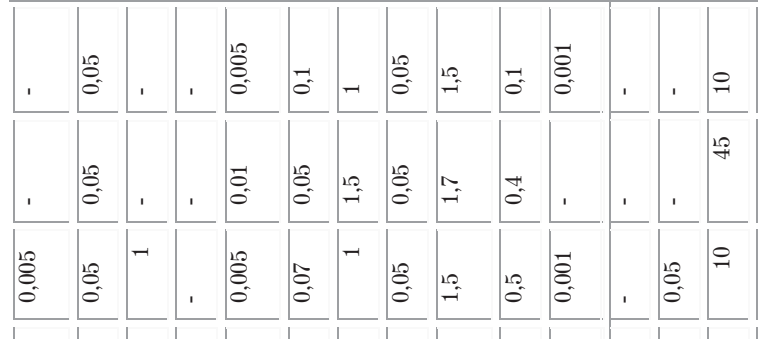

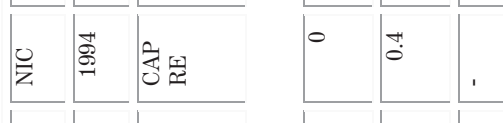

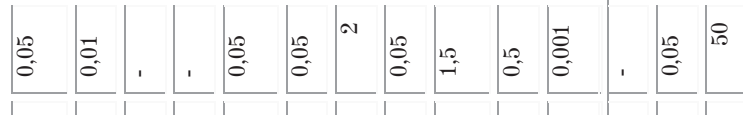

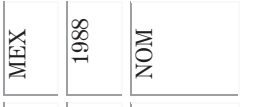

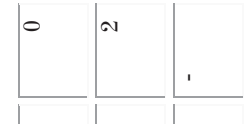

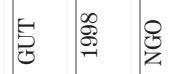

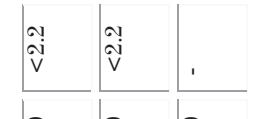

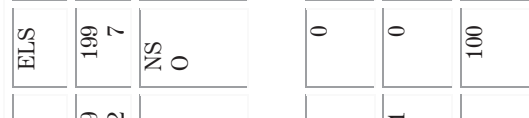

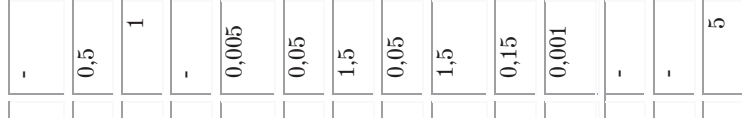

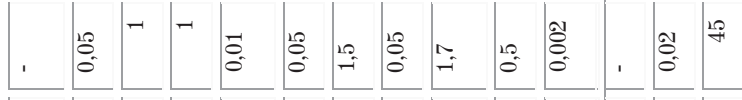

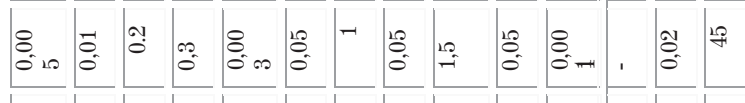

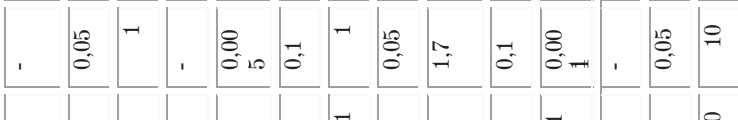

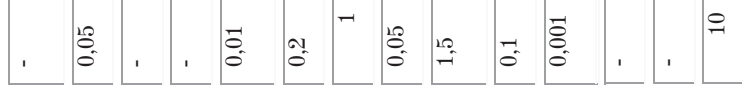

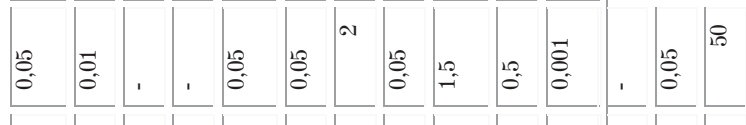

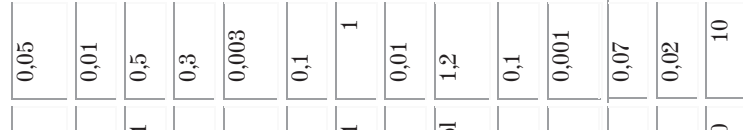

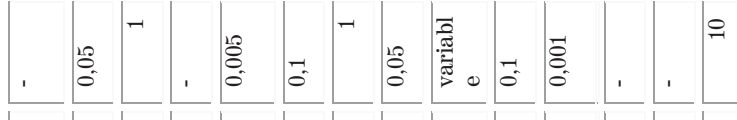

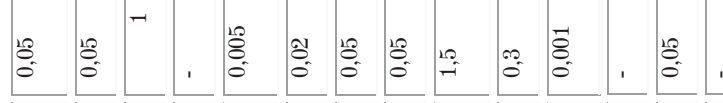

容

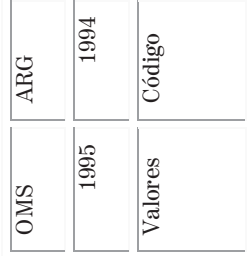

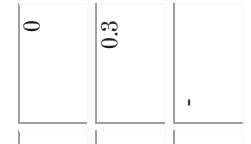

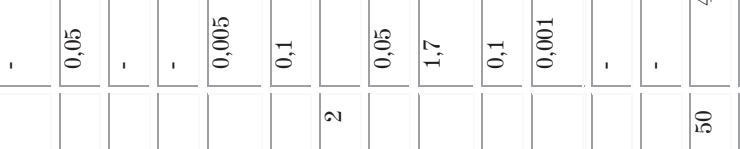

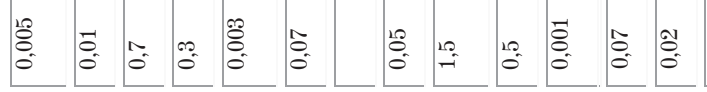

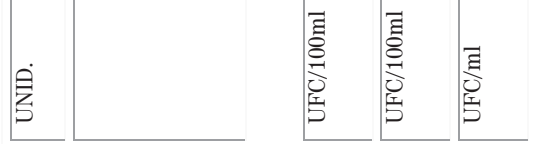

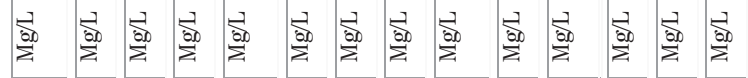

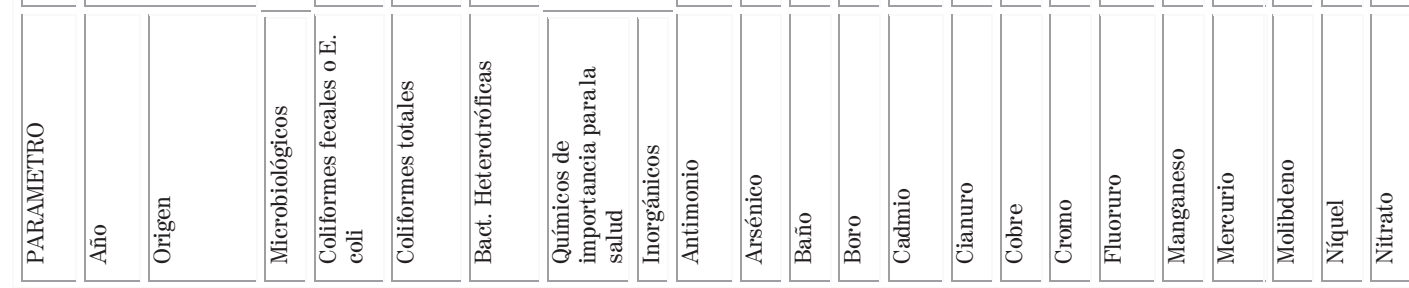




\begin{tabular}{|c|c|c|c|c|c|c|c|c|c|c|c|c|c|c|c|c|c|c|c|c|c|c|c|c|c|c|c|c|c|c|}
\hline 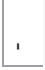 & 8 & $\overrightarrow{0}$ & & ' & ' & ' & & ' & ' & ' & ' & ' & & ' & ' & , & & ' & ' & ' & ' & ' & & & ' & ' & ' & ' & & ' \\
\hline . & $\frac{18}{8}$ & 18 & & . & ' & ' & & ' & ' & , & ' & ' & & ' & ' & , & & ' & ' & ' & ' & ' & ' & & ' & ' & ' & ' & , & . \\
\hline$\theta_{0}$ & $\frac{18}{8}$ & $\overrightarrow{0}_{0}$ & & . & , & ' & & ' & . & , & , & ' & & ' & , & , & & ' & ' & , & ' & ' & ' & & ' & ' & , & ' & & . \\
\hline - & $\stackrel{\square}{0}$ & $\ddot{0}$ & & N & จิ & , & & 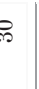 & N & 18 & $\stackrel{\circ}{\circ}$ & is. & & $R$ & q & , & & 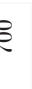 & 号 & 今్ & จิ & $\hat{o}$ & ষ্ল & & -1 & , & ষ্ল & ஜ & ৫ & $\infty$ \\
\hline , & $\frac{18}{8}$ & is & & . & ' & ' & & , & ' & , & ' & ' & & ' & ' & 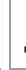 & & ' & ' & ' & ' & ' & ' & & ' & ' & ' & ' & & \\
\hline$\tilde{E}_{0}$ & $\overrightarrow{0}$ & $\ddot{E}$ & & . & ' & ' & & ' & ' & , & ' & ' & & ' & ' & , & & ' & ' & ' & ' & ' & ' & & ' & ' & ' & ' & & . \\
\hline - & $\overrightarrow{0}$ & $\overrightarrow{0}$ & & จ & 10 & ஜ & & 8 & ڤ్ & N & $\ddot{\circ}$ & 20 & & $R$ & ' & 16 & & $\xi$ & 范 & 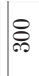 & ลิ & $\widetilde{\sim}$ & \& & 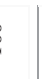 & 8 & . & n & i & ৫ & 6 \\
\hline$=$ & $\frac{18}{8}$ & $\tilde{B}_{0}$ & & . & ' & ' & & ' & ' & , & ' & ' & & ' & ' & , & & ' & ' & ' & ' & ' & ' & & ' & ' & ' & ' & ' & ' \\
\hline & $\begin{array}{l}18 \\
0 . \\
0\end{array}$ & $\overrightarrow{0}$ & & . & . & ' & & ' & ' & , & ' & ' & & ' & ' & 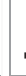 & & ' & ' & . & ' & ' & ' & & ' & ' & ' & ' & ' & ' \\
\hline & $\overrightarrow{0}$ & 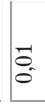 & & N & จิ & ' & & 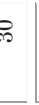 & o & 10 & $\ddot{\circ}$ & if & & $R$ & f & , & & $\xi$ & 吕 & \&్ & จิ & $\hat{o}$ & ষ্ল & & -1 & . & ৪্ল & ฉి & $\bowtie$ & $\infty$ \\
\hline$\Rightarrow$ & $\begin{array}{l}\vec{E} \\
0_{0}^{\circ}\end{array}$ & $\stackrel{5}{0}$ & & . & ' & ' & & ' & ' & , & ' & ' & & ' & ' & , & & ' & ' & ' & ' & ' & ' & & , & . & ' & ' & ' & ' \\
\hline . & $\frac{18}{8}$ & $\ddot{0}$ & & $\infty$ & ' & ' & & $\theta$ & ' & . & $\because$ & ' & & ణి & ? & f & & ' & ' & . & , & ర্ & . & & ' & ' & ' & ' & ' & ' \\
\hline 18 & $\tilde{E}_{0}$ & $\tilde{E}$ & & . & ' & ' & & ' & . & , & ' & ' & & ' & ' & 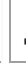 & & ' & ' & . & ' & ' & ' & & ' & ' & , & ' & ' & . \\
\hline & $\begin{array}{l}\stackrel{8}{8} \\
0 \\
0\end{array}$ & , & & $\infty$ & , & & & $\theta$ & ' & N & ' & ' & & ' & ' & $f$ & & ' & ' & ' & 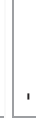 & ס্ & $m$ & & 8 & ' & ৪ & ' & ' & . \\
\hline$\infty$ & $\tilde{E}$ & $\Xi$ & & จ & จิ & $\sqrt{2}$ & & 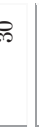 & ڤ్̀ & 10 & $\stackrel{\circ}{\circ}$ & 政 & & $R$ & f & F & & $\stackrel{8}{8}$ & 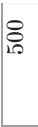 & 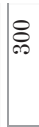 & ৯ิ & $\hat{0}$ & ষ্ল & & ৪্ন & 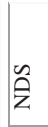 & ৪্ল & ஜ & ৪ & $\infty$ \\
\hline 尊 & $\stackrel{2}{20}$ & (5) & & $\stackrel{\partial}{\partial}$ & 晋 & & & C) & 照 & 焉 & tod & 할 & & tro & 5 & 8 & & $\frac{\partial 0}{20}$ & 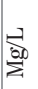 & $\frac{100}{200}$ & ప & $\frac{\delta}{\Sigma}$ & $\frac{\delta}{\Sigma}$ & 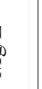 & $\delta_{\Sigma}^{\delta}$ & $\frac{\delta}{2}$ & $\frac{\delta}{\Sigma}$ & \ூ & $\frac{\delta}{\Sigma}$ & $\frac{\delta}{\Sigma}$ \\
\hline : & $\frac{\AA}{\frac{\sigma}{2}}$ & 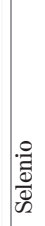 & 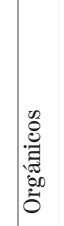 & 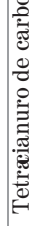 & 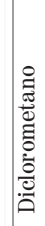 & & & 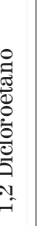 & 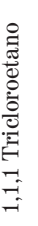 & 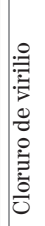 & 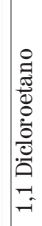 & 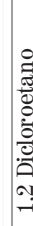 & & : & 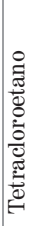 & 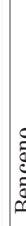 & & & : & 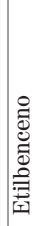 & & 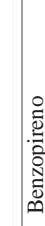 & $\begin{array}{l}8 \\
\frac{8}{8} \\
\frac{8}{2} \\
\frac{8}{2} \\
\frac{8}{2}\end{array}$ & 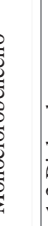 & 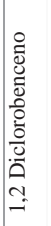 & 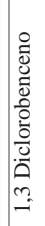 & 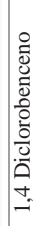 & 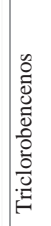 & 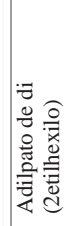 & 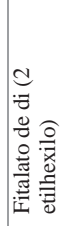 \\
\hline
\end{tabular}




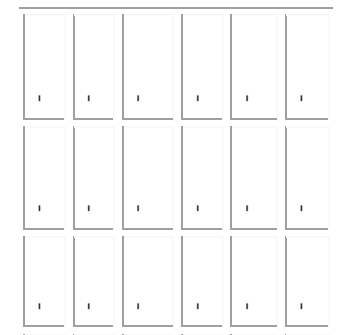

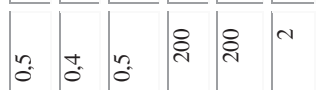

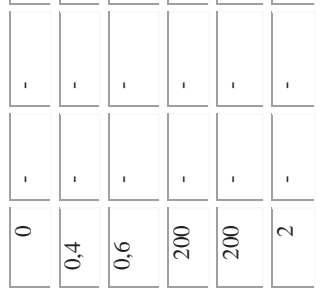

80

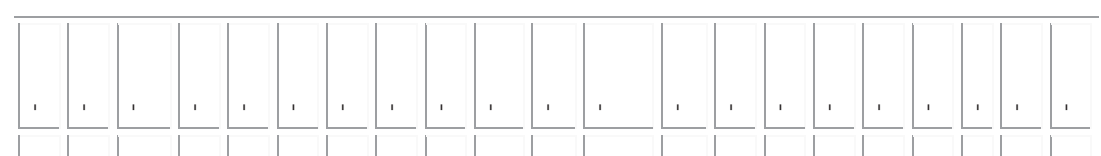

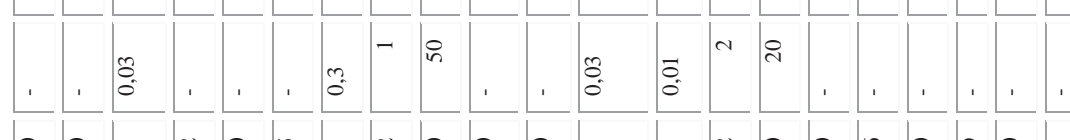
a o A $\quad$ m in 8 $\infty$ \& m

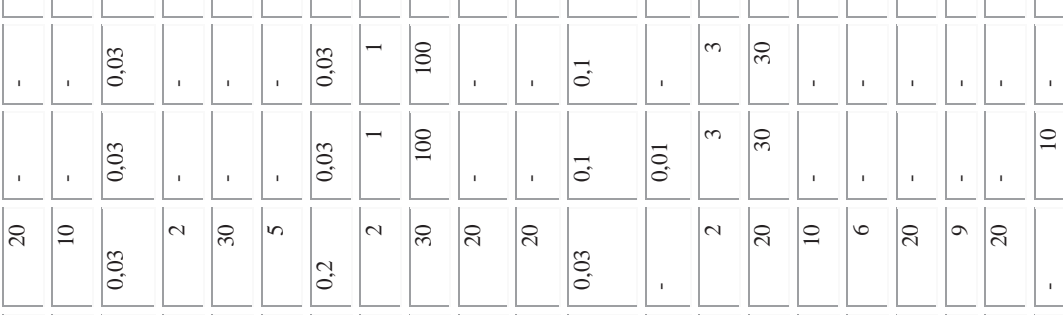
n.

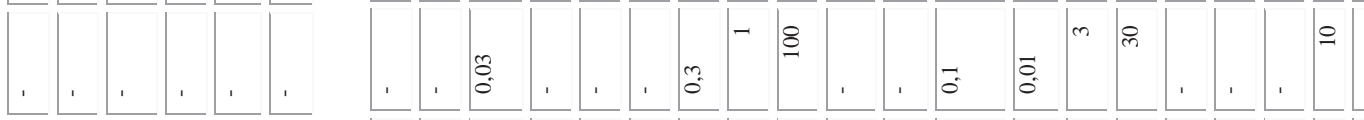

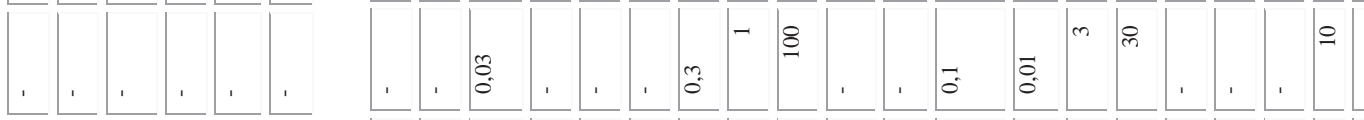
:.'.:.

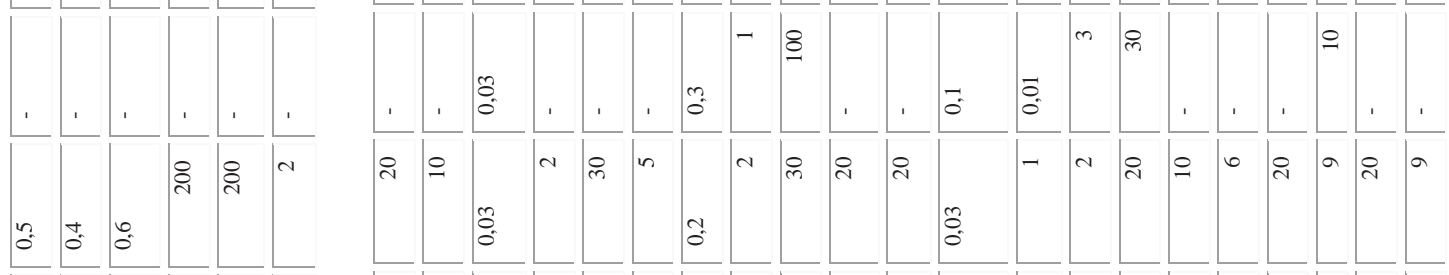

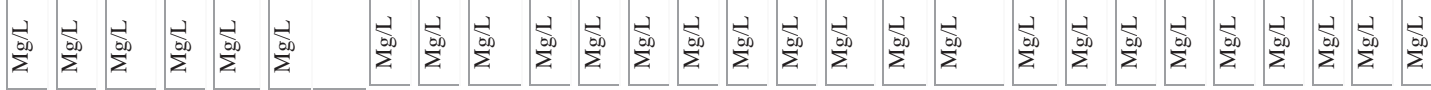

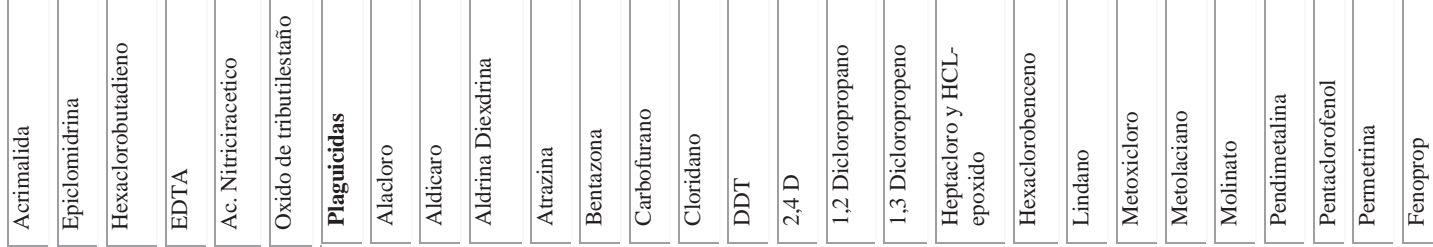




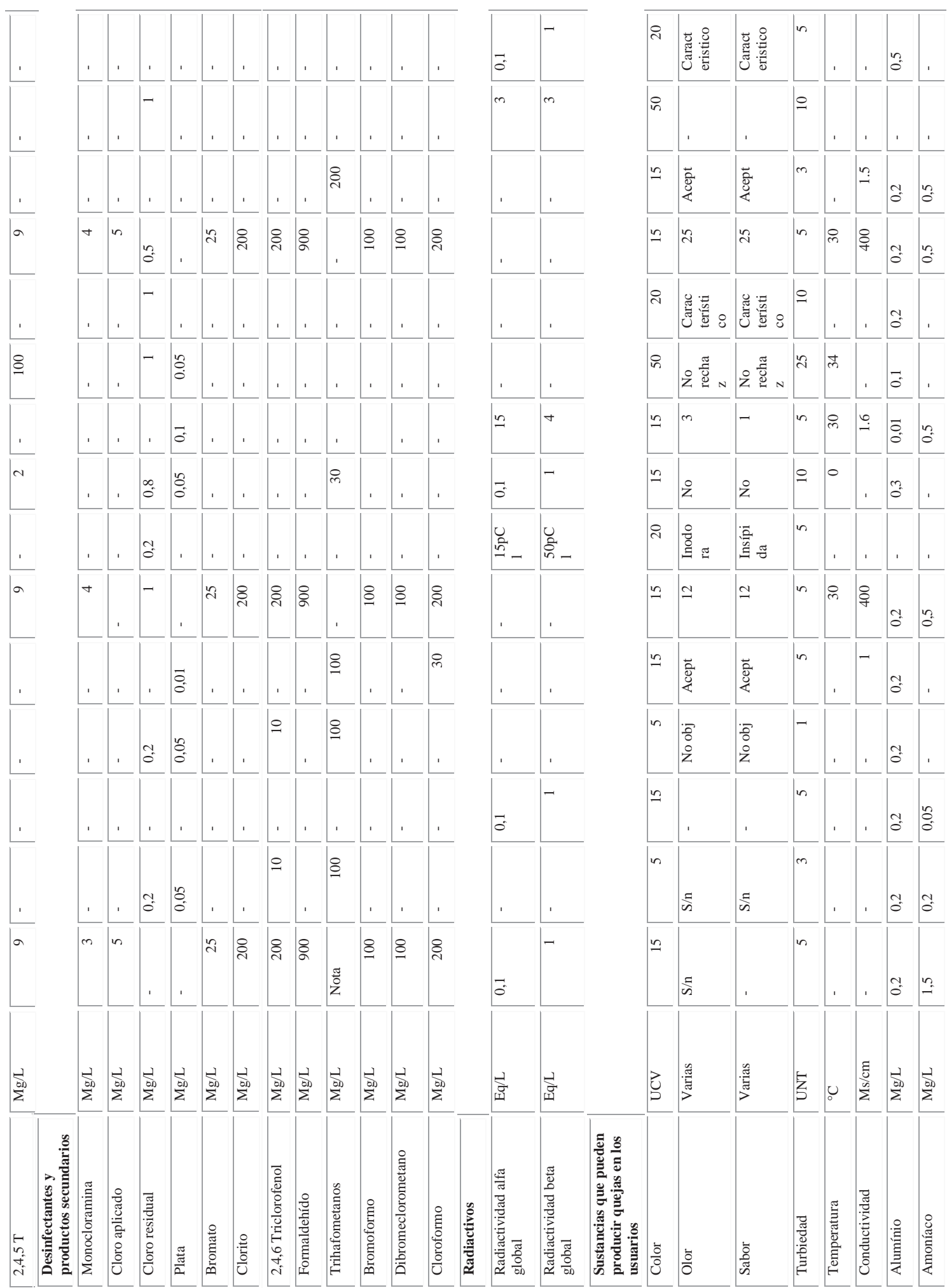




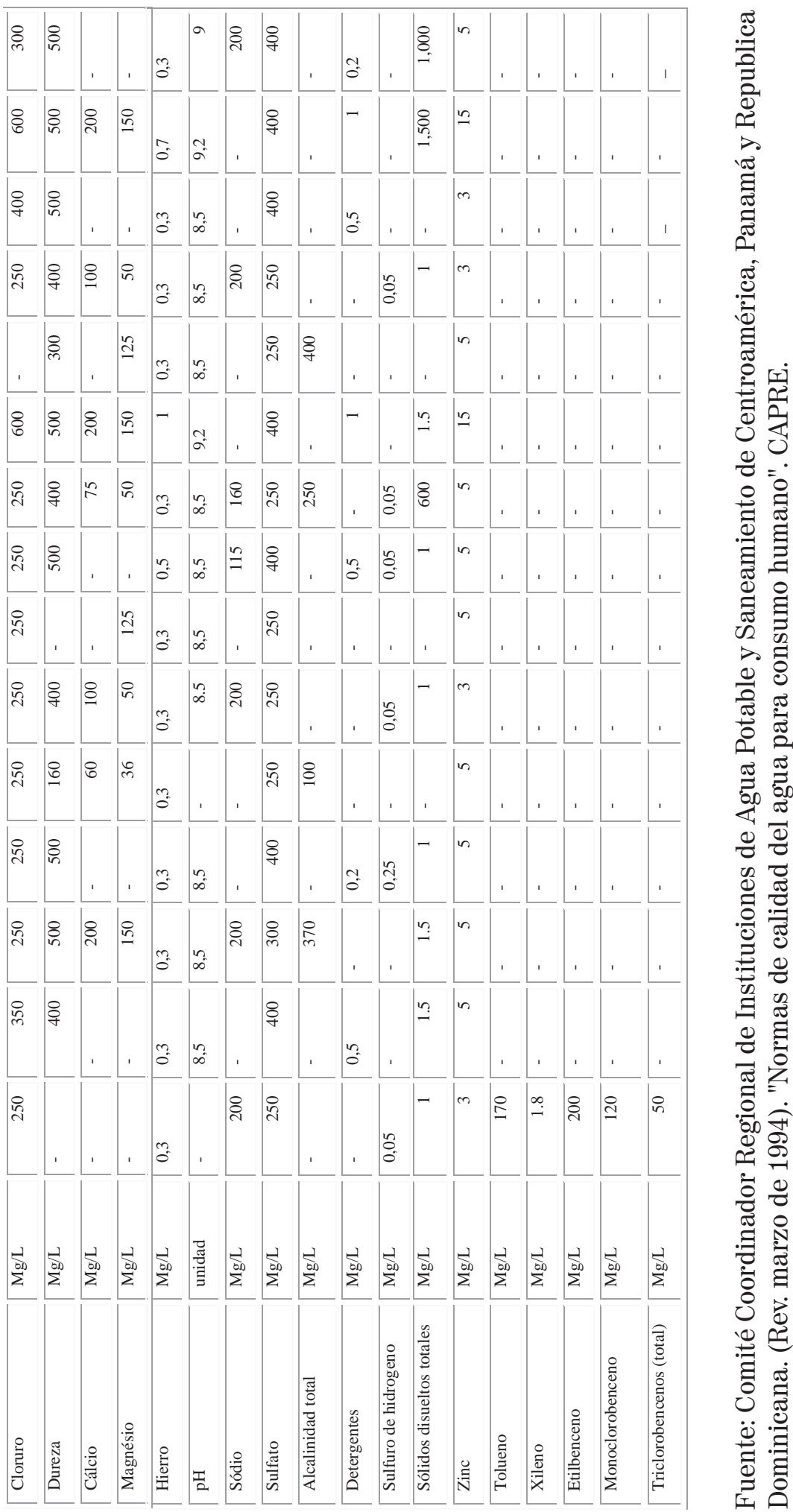

